\title{
Ruptured temporal horn aneurysm associated with Moyamoya collateral vessel coexisting with contralateral arteriovenous malformation - technical note with clinical vignette
}

\author{
Alejandro Feria ${ }^{1}$, Grzegorz Brzezicki ${ }^{2}$ \\ ${ }^{1}$ Department of Internal Medicine, University of Kentucky, United States \\ ${ }^{2}$ Department of Neurosurgery, University of Florida, College of Medicine Jacksonville, United States
}

\begin{abstract}
The co-occurrence of a brain arteriovenous malformation, Moyamoya Disease, and intracranial aneurysm is exceedingly rare. We report the third case of this disease constellation, and the first where the aneurysm arises from the Moyamoya collateral vessel. We review the relevant literature and discuss proposed pathophysiological mechanisms and clinical implications.
\end{abstract}

Key words: arteriovenous malformation, Moyamoya Disease, aneurysm, collateral aneurysm

(Neurol Neurochir Pol 2021; 55 (1): 102-106)

\section{Introduction}

Brain arteriovenous malformations (AVM) are masses of disordered cerebral angioarchitecture with 2-3\% annual rate for intracranial haemorrhage, sometimes associated with intracranial aneurysms on feeding vessels related to high flow demand [1-3]. Moyamoya Disease (MMD) is a progressive steno-occlusive arteriopathy of the Circle of Willis associated with intracranial aneurysms [4]. MMD associated with AVM is rare, with 20 cases reported, and co-occurring AVM, MMD and intracranial aneurysm is exceedingly rare, with only two previous cases $[5,6]$. We report a third case of co-occurring AVM with contralateral MMD and ruptured intraventricular Moyamoya collateral vessel aneurysm.

\section{Materials and methods}

Technical report with anonymised case vignette and literature review. Therefore IRB/ethics committee approval was not required from the authors' home institutions.

\section{Case report}

A sexagenarian female presented for reevaluation for a known Spetzler-Martin Grade V AVM diagnosed 20 years earlier after a grand mal seizure [7]. She had been previously evaluated by multiple neurosurgeons over many years, advised against intervention, and recommended follow-up imaging. She had a normal neurological exam, without seizures for 6.5 years, on levetiracetam and phenytoin, reporting stable manageable headaches. Most recent magnetic resonance angiography (MRA) four years prior demonstrated grade $V$ left parietal AVM fed by large left middle cerebral artery (MCA) branches with contribution from the left anterior cerebral artery (ACA). The right MCA appeared diminutive with possible collateral formation. The patient declined follow-up imaging, but agreed to return if new symptoms arose.

Three months later, the patient presented to the emergency room with sudden onset pressure-like left parietal headache after bending over. Neurological exam revealed only mild dysmetria. Head computerised tomography (CT) showed a purely

Address for correspondence: Grzegorz Brzezicki, Department of Neurosurgery, University of Florida, College of Medicine Jacksonville, Jacksonville, Florida, United States, e-mail: Grzegorz.Brzezicki@jax.ufl.edu 
intraventricular haemorrhage originating in the right lateral ventricle extending to left lateral, 3rd and 4th ventricles without hydrocephalus (Fig. 1A, B). Computerised tomography angiography (CTA) of the head demonstrated the known left grade $\mathrm{V}$ $\mathrm{AVM}$ (Fig. 1A) and punctate contrast enhancement in the right temporal horn (Fig. 1B). Catheter angiography demonstrated that the grade V AVM fed predominantly from left MCA and ACA branches (Fig. 1C, D) and chronically occluded right MCA with Moyamoya-type collaterals supplying the majority of the right MCA territory (Fig. 1E). A $1.8 \times 1.2 \mathrm{~mm}$ right temporal horn aneurysm associated with Moyamoya collateral vessels was visualised (Fig. 1F). Right external carotid
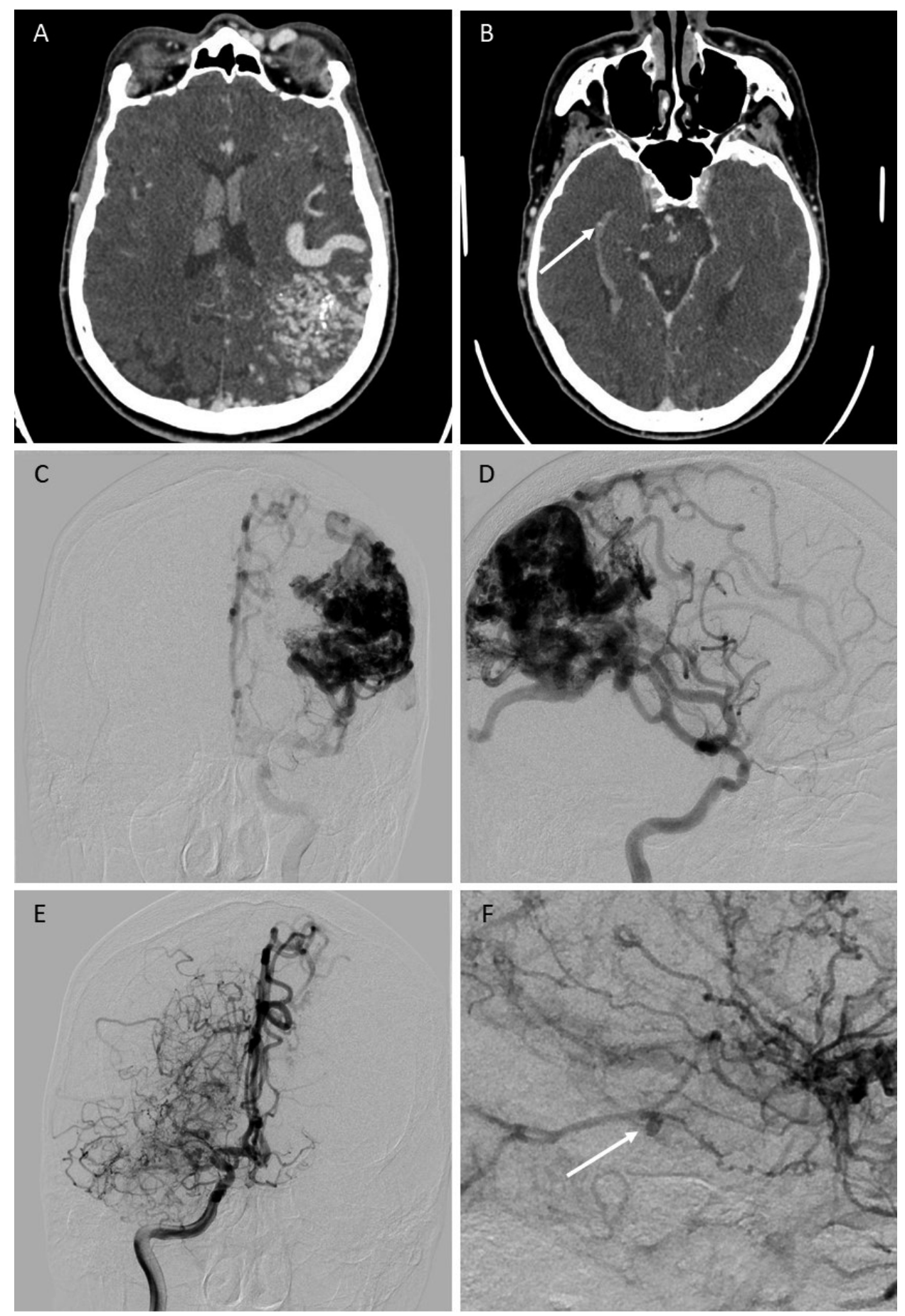

Figure 1. CTA: left parietal Spetzler-Martin grade V AVM (A) and focus of contrast enhancement in right temporal horn within blood clot - white arrow (B). Left internal carotid artery catheter angiogram: left parietal AVM with main feeders from left MCA and ACA, deep and superficial drainage, no flow-related aneurysms were identified (C, D). Right internal carotid artery catheter angiogram: right MCA occlusion with Moyamoya-type collaterals $(E)$ and $1.8 \times 1.2 \mathrm{~mm}$ right temporal horn aneurysm (white arrow) originating from distal Moyamoya collateral vessel (F) 
Table 1. Reported cases of co-occurring AVM, Moyamoya Disease, and intracranial aneurysm

\begin{tabular}{|c|c|c|c|c|c|c|c|c|}
\hline Authors & $\begin{array}{l}\text { Age / } \\
\text { /Sex }\end{array}$ & $\begin{array}{c}\text { Presen- } \\
\text { tation }\end{array}$ & $\begin{array}{c}\text { AVM } \\
\text { location }\end{array}$ & $\begin{array}{l}\text { AVM associated } \\
\text { with Moyamoya } \\
\text { collaterals }\end{array}$ & $\begin{array}{l}\text { Moyamoya } \\
\text { location }\end{array}$ & $\begin{array}{c}\text { Aneurysm } \\
\text { location }\end{array}$ & Treatment & $\begin{array}{c}\text { Follow- } \\
\text {-up }\end{array}$ \\
\hline $\begin{array}{l}\text { Yu et al. } 2016 \\
\text { [9] }\end{array}$ & $42 / F$ & SAH & $\begin{array}{l}\text { Left occi- } \\
\text { pital }\end{array}$ & No & $\begin{array}{l}\text { Bilateral } \\
\text { MCA and } \\
\text { right A1 }\end{array}$ & AComA & $\begin{array}{l}\text { Surgical clipping of } \\
\text { AComA aneurysm. Con- } \\
\text { servative management } \\
\text { for AVM and Moyamoya }\end{array}$ & 6 months \\
\hline $\begin{array}{l}\text { Mills et al. } \\
2018 \text { [10] }\end{array}$ & $46 / F$ & $\begin{array}{l}\text { Ischaemic } \\
\text { (infarct) }\end{array}$ & $\begin{array}{l}\text { Left } \\
\text { frontal }\end{array}$ & No & $\begin{array}{l}\text { Left ICA, } \\
\text { MCA, and } \\
\text { ACA }\end{array}$ & $\begin{array}{c}\text { Right } \\
\text { distal A1 }\end{array}$ & $\begin{array}{l}\text { Left direct external } \\
\text { carotid artery M2 radial } \\
\text { artery graft anastomosis, } \\
\text { with left indirect super- } \\
\text { ficial temporal artery } \\
\text { encephalduroarteriosyn- } \\
\text { angiosis for Moyamoya. } \\
\text { Stereotactic radiosurgery } \\
\text { for AVM. Endovascular } \\
\text { coiling of A1 aneurysm }\end{array}$ & 3 years \\
\hline $\begin{array}{l}\text { Presented } \\
\text { case }\end{array}$ & $63 / F$ & $\begin{array}{l}\text { Seizures } \\
\text { (AVM), IVH } \\
\text { (aneurysm) }\end{array}$ & $\begin{array}{l}\text { Left fron- } \\
\text { toparietal }\end{array}$ & No & Right M1 & $\begin{array}{l}\text { Right } \\
\text { temporal } \\
\text { Moya- } \\
\text { moya } \\
\text { collaterals }\end{array}$ & $\begin{array}{l}\text { Attempted surgical } \\
\text { clipping of Moyamoya } \\
\text { collateral aneurysm } \\
\text { with subsequent vessel } \\
\text { sacrifice. Conservative } \\
\text { management for AVM } \\
\text { and Moyamoya }\end{array}$ & 1 year \\
\hline
\end{tabular}

artery injection demonstrated moderate pial collaterals. The aneurysm was not amenable to endovascular intervention given that it was a distal, tortuous, small calibre vessel, so we proceeded with craniotomy and aneurysm obliteration with possible vessel sacrifice. The patient underwent typical right temporal craniotomy sparing the STA and middle meningeal artery to preserve collaterals with neuronavigation-assisted transcortical approach through middle temporal gyrus to the right temporal horn. The aneurysm and parent vessel were dissected free from surrounding clot within the ventricle. The feeding vessel and aneurysm appeared frail, and during clip placement the aneurysm partially tore at the neck which was partially controlled by clip repositioning. Eventually, the parent vessel was sacrificed with bipolar cautery. Immediate postoperative angiography confirmed complete obliteration of right temporal horn aneurysm. The patient had an uneventful postoperative course. One-year follow-up CTA demonstrated no new aneurysms with stable AVM. The patient had one grand mal seizure while hospitalised for a subsequent myocardial infarction requiring percutaneous coronary intervention. She continues to be actively surveilled.

\section{Discussion}

Brain AVMs are masses of disordered cerebral angioarchitecture with direct arterial to venous connections and no intervening capillary network, often intermixed with gliotic tissue. With an estimated prevalence of $18 / 100,000$ per year, AVM are believed to cause $1-2 \%$ of strokes and $9 \%$ of subarachnoid haemorrhages [8]. Intracerebral haemorrhage is the most common initial presentation for AVMs (42-72\%) [9].
MMD commonly affects the bilateral internal carotid arteries (ICA) and their terminal branches, with resultant proliferation of numerous collateral vessels giving the classic angiographic finding of a 'puff of smoke' [10].

Cerebral aneurysm associated with MMD may result from altered cerebrovascular flow dynamics following carotid artery stenosis and pathological vessel architecture $[11,12]$. These aneurysms commonly occur at Circle of Willis branches, anterior communicating artery (AComA) and basilar bifurcation; less so from MMD collaterals [4]. MMD presenting with ruptured collaterals or collateral aneurysms has a different clinical course than classical MMD, and unique treatment strategies are proposed $[6,10]$.

MMD associated with AVM is rare [13]. The majority were co-identified at presentation and associated with Moyamoya collaterals. A Moyamoya-like phenomenon with AVM may be the result of increased cerebral blood flow through the AVM causing turbulent carotid bifurcation flow and resultant focal intimal hyperplasia and stenosis [14].

Alternatively, altered flow dynamics and the vascular steal phenomenon can cause focal areas of ischaemia driving excessive basic fibroblast growth factor production and proliferation of fibroblasts, vascular endothelium, and smooth muscle cells $[4,15]$. The case we present has well-documented longstanding AVM and contralateral MMD which appear to be separate, coexisting entities without angiographically documented feeders from right MCA territory.

The co-occurrence of AVM, MMD, and aneurysm is very rare (Tab. 1). The first case was reported in a 42 -year-old woman with subarachnoid haemorrhage and left occipital posterior circulation AVM, bilateral MMD, and AComA 
aneurysm [5]. The second case was a 46-year-old woman with stroke symptoms and unruptured left frontal AVM, left-sided Moyamoya-like obliterative arteriopathy and unruptured right ACA aneurysm [6]. Our case is unique in that it presented with isolated intraventricular haemorrhage from a ruptured MMD collateral aneurysm.

\section{Clinical implications}

Moyamoya collateral aneurysms refer to dilated thalamoperforating artery (TPA) and lenticulostriate arteries (LSA) with associated aneurysm [12]. LSA aneurysms occur as type I saccular aneurysms (dome spares the LSA) or type II fusiform aneurysms (dome incorporates the LSA) [16]. Satisfactory management has been described using open surgical clipping with either sparing or obliteration of the LSA $[16,17]$. When these aneurysms rupture, distal LSA preservation is rarely possible, and frequently associated with pseudoaneurysm formation and haematoma. Endovascular therapy for LSA Moyamoya aneurysms remains technically challenging due to tortuous parent vessels, friable tissue, and small vessel calibre. However, successful LSA aneurysm endovascular treatments have been described using liquid embolic agents [18]. There are also reports using superior temporal artery (STA)-MCA anastomosis with encephaloduromyosynagiosis resulting in LSA aneurysm disappearance, STA-MCA bypass with microsurgical clipping, and spontaneous aneurysm resolution after conservative management $[15,19]$. It appears some LSA aneurysms may resolve spontaneously if effective collateral networks are established, even without open clipping or endovascular therapy, so long as haemodynamic stress on the LSA is reduced.

TPA aneurysms are comparatively rare in MMD and technically challenging as the TPA originates from the tip of the basilar artery. A ruptured left TPA aneurysm which developed after right encephaloduromyoarteriosynagiosis was treated with combined surgical excision and left encephalomyosynagiosis [20]. These aneurysms are extremely rare, with no effective management guidelines.

\section{Conclusion}

This case illustrates the necessity of thorough diagnostic evaluation of patients with cerebrovascular bleed and a known high-risk cerebrovascular lesion such as AVM. In this case, intraventricular haemorrhage with greater ventricular casting contralateral to the AVM was discordant with the expected pattern of ruptured AVM, prompting further evaluation revealing a MMD collateral aneurysm haemorrhage.

We have here reported the third case of co-occurring brain AVM, MMD, and intracranial aneurysm, and discussed technical considerations for its management. The underlying pathophysiology remains poorly understood. Complex neurosurgical cases involving multiple intracranial pathologies require individualised therapy designed case-by-case.

\section{Abbreviations:}

AVM - arteriovenous malformation; MMD - Moyamoya Disease; MRA — magnetic resonance angiography; MCA middle cerebral artery; ACA - anterior cerebral artery; CT computerised tomography; CTA - computerised tomography angiography; ICA — internal carotid artery; AComA - anterior communicating artery; TPA — thalamoperforating artery; LSA - lenticulostriate artery; STA — superior temporal artery

Conflicts of interests: The authors declare that the article content was composed in the absence of any commercial or financial relationship that could be construed as a potential conflict of interest.

Bioethics Committee: Chart review and review of literature. This study is a technical report with anonymised case vignette and literature review. Therefore explicit IRB/ethics committee approval was not required from the authors' home institutions. This study conforms with all recognised bioethical standards. Contributions: All authors approved the final article.

Feria: methodology, data curation and formal analysis, writing original draft, review and editing.

Brzezicki: conceptualisation, methodology, data curation and formal analysis, review and editing, supervision.

Funding: The authors received no funding for this article.

\section{References}

1. Gross B, Du R. Natural history of cerebral arteriovenous malformations: a meta-analysis. Journal of Neurosurgery. 2013; 118(2): 437 443, doi: 10.3171/2012.10.jns121280.

2. Kim H, Al-Shahi Salman R, McCulloch CE, et al. MARS Coinvestigators. Untreated brain arteriovenous malformation: patient-level meta-analysis of hemorrhage predictors. Neurology. 2014; 83(7): 590597, doi: 10.1212/WNL.0000000000000688, indexed in Pubmed: 25015366.

3. Mohr JP, Parides MK, Stapf C, et al. international ARUBA investigators. Medical management with or without interventional therapy for unruptured brain arteriovenous malformations (ARUBA): a multicentre, non-blinded, randomised trial. Lancet. 2014; 383(9917): 614-621, doi: 10.1016/S0140-6736(13)62302-8, indexed in Pubmed: 24268105.

4. Herreman F, Nathal E, Yasui N, et al. Intracranial Aneurysms in Moyamoya Disease: Report of Ten Cases and Review of the Literature. Cerebrovascular Diseases. 1994; 4(5): 329-336, doi: 10.1159/000108503.

5. Yu J, Yuan Y, Zhang D, et al. Moyamoya disease associated with arteriovenous malformation and anterior communicating artery aneurysm: A case report and literature review. Exp Ther Med. 2016; 12(1): 267 271, doi: 10.3892/etm.2016.3289, indexed in Pubmed: 27347048.

6. Mills MT, Zafar A, Choudhari KA, et al. Management of Concomitant Moyamoya Disease, Arterial Venous Malformation, and Intracranial Aneurysm: Case Illustration, Literature Review, and Management Algorithm. World Neurosurg. 2018; 119: 262-266, doi: 10.1016/j. wneu.2018.08.017, indexed in Pubmed: 30107248.

7. Spetzler RF, Martin NA. A proposed grading system for arteriovenous malformations. J Neurosurg. 1986; 65(4): 476-483, doi: 10.3171/ jns.1986.65.4.0476, indexed in Pubmed: 3760956. 
8. Al-Shahi R, Warlow C. A systematic review of the frequency and prognosis of arteriovenous malformations of the brain in adults. Brain. 2001; 124(Pt 10): 1900-1926, doi: 10.1093/brain/124.10.1900, indexed in Pubmed: 11571210.

9. Friedlander RM. Clinical practice. Arteriovenous malformations of the brain. N Engl J Med. 2007; 356(26): 2704-2712, doi: 10.1056/NEJMcp067192, indexed in Pubmed: 17596605.

10. Suzuki J, Kodama N. Moyamoya disease-a review. Stroke. 1983; 14(1): 104-109, doi: 10.1161/01.str.14.1.104, indexed in Pubmed: 6823678.

11. $\mathrm{Yu} \mathrm{JL}$, Wang $\mathrm{HL}, \mathrm{Xu} \mathrm{K}$, et al. Endovascular treatment of intracranial aneurysms associated with moyamoya disease or moyamoya syndrome. Interv Neuroradiol. 2010; 16(3): 240-248, doi: 10.1177/159101991001600302, indexed in Pubmed: 20977854.

12. Zhang $L$, Xu K, Zhang $Y$, et al. Treatment strategies for aneurysms associated with moyamoya disease. Int J Med Sci. 2015; 12(3): 234 242, doi: 10.7150/ijms.10837, indexed in Pubmed: 25678840.

13. Noh JH, Yeon JeY, Park JH, et al. Cerebral arteriovenous malformation associated with moyamoya disease. J Korean Neurosurg Soc. 2014; 56(4): 356-360, doi: 10.3340/jkns.2014.56.4.356, indexed in Pubmed: 25371789.

14. Mawad ME, Hilal SK, Michelsen WJ, et al. Occlusive vascular disease associated with cerebral arteriovenous malformations. Radiology. 1984; 153(2): 401-408, doi: 10.1148/radiology.153.2.6484172, indexed in Pubmed: 6484172.
15. Kalani MY, Martirosyan NL, Nakaji P, et al. Microsurgical clipping of an unruptured lenticulostriate aneurysm. J Clin Neurosci. 2012; 19(11): 1578-1580, doi: 10.1016/j.jocn.2012.03.006, indexed in Pubmed: 22925414.

16. Gandhi CD, Gilad R, Patel AB, et al. Treatment of ruptured lenticulostriate artery aneurysms. J Neurosurg. 2008; 109(1): 28-37, doi: 10.3171/JNS/2008/109/7/0028, indexed in Pubmed: 18590430.

17. Sakai $\mathrm{K}$, Mizumatsu S, Terasaka K, et al. Surgical treatment of a lenticulostriate artery aneurysm. Case report. Neurol Med Chir (Tokyo). 2005; 45(11): 574-577, doi: 10.2176/nmc.45.574, indexed in Pubmed: 16308516.

18. Chalouhi N, Tjoumakaris S, Gonzalez LF, et al. Onyx embolization of a ruptured lenticulostriate artery aneurysm in a patient with moyamoya disease. World Neurosurg. 2013; 80(3-4): 436.e7436.10, doi: 10.1016/j.wneu.2012.03.030, indexed in Pubmed: 22484074.

19. Ni W, Xu F, Xu B, et al. Disappearance of aneurysms associated with moyamoya disease after STA-MCA anastomosis with encephaloduro myosynangiosis. J Clin Neurosci. 2012; 19(3): 485-487, doi: 10.1016/j.jocn.2011.05.036, indexed in Pubmed: 22281383.

20. Leung GK, Lee R, Lui WM, et al. Thalamo-perforating artery aneurysm in Moyamoya disease - case report. Br J Neurosurg. 2010; 24(4): 479-481, doi: 10.3109/02688697.2010.487128, indexed in Pubmed: 20515265. 